\title{
Trans Urethral Resection of Prostate for Symptomatic BPH in Rural Area
}

\author{
AMIT KUMAR, DEVENDRA KUMAR SHIWACH
}

\section{ABSTRACT}

Introduction: Benign Prostatic Hyperplasia (BPH) is quite a common disease in the older male with increasing incidence with age. Many patients require surgical treatment and presently TURP(Trans Urethral Resection of Prostate) is considered the gold standard in surgical management of bladder outlet obstruction but is still not routinely available in most resource poor areas.

Aim: To observe and assess the outcome of TURP being done in our institution hospital which is situated in rural area and catering mainly to the surrounding region.

Materials and Methods: The records of patients who presented to the surgical OPD with LUTS and were assessed to undergo TURP for prostatic hyperplasia. We present our experience with series of 47 patients and posit that TURP can be used for most patients presenting with $\mathrm{BPH}$ in peripheral areas.
Results: In the study period 47 TURP procedures were performed for $\mathrm{BPH}$. The mean age of the cohort was 67.9 years; ( ranging from 56 to 84 years). The mean prostatic volume was 44.06 grams (range 32 to 76 grams) and mean operating time was 48 minutes (range 29 to 85 minutes). Blood transfusion was required in 3 patients (6.3\%). No patients required open intervention and there were no mortalities. The common complications were bleeding (12\%), UTI and clot retention.

Conclusion: TURP is not available to majority of rural population having symptomatic benign prostatic hyperplasia (BPH) due to lack of facility but remains the treatment of choice provided trained surgeons and facilities are there. The overall cost of TURP is marginally higher for an average rural patient as compared to open surgery but is worthwhile in view of its inherent minimal trauma, short hospital stay and early recovery and huge cost advantage over newer therapies like HoLEP or PVP.

\section{INTRODUCTION}

Benign Prostatic Hyperplasia (BPH) is a common disease affecting 40 to $60 \%$ of males above the age of 60 years and the incidence increases progressively with age depending upon the age, family history and prostate size of the patient [1,2]. TURP has been the gold standard in treatment of prostatic hyperplasia requiring surgery against which all the newer modalities are compared as it provides durable treatment in follow up till 22 years.

Since, the introduction of medical therapy for BPH and LUTS in the 1980s, there has been a well documented increasing trend to manage BPH by medical means using alpha blockers and 5 ARI [3].

Those having persistent symptoms or who have failed trial of catheter removal were taken up for surgery. Increasingly such treatment is being provided by laser ablation of prostate using HoLEP, GreenLight or TUMT. Some researchers have advocated continued use of Open prostatectomy in patients presenting in peripheral medical centres [4]. Trans Urethral resection of Prostate (TURP) remains an effective treatment for bladder outlet obstruction due to prostatic growth [5]. TURP has a steep learning curve which is better supervised by a senior person reducing the incidence of complications and need for re-intervention [6]. For urologists in peripheral areas there are numerous challenges in sourcing instruments and consumables. The procedure is not routinely available in most public institutions due to lack of necessary infrastructure and trained personnel.

In our opinion TURP can be easily undertaken in rural hospitals having adequate staff and observation facilities. The initial investment is easily offset by the treatment provided and is reflected in patient preference when offered. In this study we review our experience with TURP as an alternative to open prostatectomy in properly evaluated patients to determine its efficacy and implement in centres where vapour prostatectomy or HoLEP is not possible. 


\section{MATERIALS AND METHODS}

This is a retrospective study in Rama Medical College Hospital and Research Center, Hapur, India, providing to rural population of Uttar Pradesh and Uttarakhand in Northern India. The medical records of patients undergoing prostatic resection in the period of October 2012 to August 2014 were examined and taken up for analysis. The parameters included were age, size or volume of prostate as determined by transvesical ultrasound, preoperative Haemoglobin, serum PSA levels, post operative blood transfusion requirement if needed, duration of Surgery, length of stay and immediate and late complications along with overall outcome. Informed consent was routinely obtained from all the patients for use of records for research purposes. Clearance from the ethical review board was taken for the study.

Patients presenting in OPD or Rural surgical Clinics with LUTS (Lower Urinary Tract symptoms) were evaluated for the cause and patients diagnosed to have BPH were further evaluated for prostatic size, associated co-morbidities and fitness for anaesthesia and to undergo TURP in lithotomy position. Patients assessed to have prostatic size more than 100 grams, those having associated vesical calculus or undergoing open prostatectomy were not included. In total 47 patients were included in the study. Patients were anaesthetized using $3 \mathrm{ml}$ of Bupivacaine Heavy with $0.5 \mathrm{ml}$ of Clonidium as sub arachnoid block given under aseptic conditions. Cystourethroscopy was done using 19 Fr Sheath with 30 degree Karl Storz cystoscope to evaluate urethra, prostate and bladder mucosa. TURP was done using 26 Fr Karl Storz sheath and resectoscope with unipolar cautery removing prostatic tissues from median and both lateral lobes till just proximal to the verumontanum using cutting current at $150 \mathrm{w}$ and coagulation at 100W till capsule was barely visible. $1.5 \%$ Glycine was used as irrigating fluid at a height of about 1 metre from the patient. Glycine is readily available here, though some have use 5\% dextrose or sterile water for the same [7]. 20 or 22 Fr three way Foley's catheter was inserted and inflated till $50 \mathrm{ml}$ with application of traction and irrigated using normal saline till the effluent was clear for a while.

The traction was removed in 8 to 24 hours and in most cases the catheter was removed on the $2^{\text {nd }}$ or $3^{\text {rd }}$ day and patient was discharged if he could void freely.

All tissues removed were sent for histopathological examination.

The data gathered was tabulated and analysed.

\section{RESULTS}

In total 47 patients had undergone TURP for $\mathrm{BPH}$. The age range varied from 56 years to 84 years with an average of 67.94 years

The weight of prostate varied from 32 grams to 76 grams with an average of 44.06 grams. On cystoscopic examination or ultrasound comment 12 patients had prominent median lobe while in the others there was enlargement of bilateral lateral lobes only.

At presentation 7 patients had haemoglobin level less than 12 $\mathrm{gm} \%$ and it varied from 9 to $16 \mathrm{gm} \%$. The average $\mathrm{Hb} \%$ in the group was $13.02 \mathrm{gm} \%$.
In the post operative period 3 patients had to be transfused blood of which 2 patients needed 2 units of packed RBC. Complications observed in the immediate post operative period were prolonged or excessive bleeding from the prostatic bed was seen in 6 patients necessitating longer irrigation and length of stay. Breach of prostatic Capsule or tear was observed in two patients and in one case was associated with leak of irrigating fluid into the peritoneal cavity. This resolved on conservative measures only.

Four patients had clot retention or leakage along the side of Foley's in the post operative period possibly due to dislodgement of clot $(8.5 \%)$ or pause in irrigation. Four patients had UTI or dysuria in the post operative period. One patient (2.12\%) developed retention 10 days after removal of catheter and was resolved on dilatation of urethral tract. Three patients (6.3\%) had persistent dribbling in the post operative period due to weakness of sphincters. This improved over a month in two patients while one patient had leakage till about 4 months before resolution. None of them had any persistent urinary incontinence in this series.

All patients had symptomatic and subjective improvement in urination following TURP. None of the patients had TUR Syndrome or erectile dysfunction. There was no mortality in this series.

Among the 47 patients taken up for surgery 12 were under treatment for hypertension and 4 more were found to have raised blood pressure during workup and were started on medication. Four patients in this series had diabetes mellitus. Six patients had COPD or asthma but had no complication attributed to it during the operation. Two patients having some ECG changes had no difficulty in undergoing the operation. One patient presenting with acute urinary retention had TURP 7 years back and operated for CABG (coronary angio by pass graft) 2 years earlier and was on aspirin and clopidogrel. He underwent repeat TURP after stopping clopidogrel 5 days before surgery and restarted later that day. He had an episode of delayed haematuria on 15th postoperative day and no other problems.

Catheterization time varied from 18 hours to 7 days with an average of 2.8 days.

\begin{tabular}{|l|c|l|}
\hline \multicolumn{1}{|c|}{ Complications } & Numbers (\%) & \multicolumn{1}{|c|}{ Outcome } \\
\hline Bleeding & $6(12.7)$ & Transfusion or long irrigation. \\
\hline Clot Retention & $4(8.5)$ & Flushed and improved \\
\hline Dribbling of urine & $3(6.3)$ & $\begin{array}{l}\text { Resolved on conservative } \\
\text { treatment. One had difficulty } \\
\text { for 4 months }\end{array}$ \\
\hline Urinary Retention & $1(2.1)$ & Needed Dilatation \\
\hline Dysuria & $4(8.5 \%)$ & Improved on antibiotics \\
\hline Capsular Tear & $2(4.2)$ & Improved \\
\hline $\begin{array}{l}\text { Collection of } \\
\text { Irrigating fluid in } \\
\text { peritoneal Cavity }\end{array}$ & $1(2.1 \%)$ & Improved \\
\hline
\end{tabular}

[Table/Fig-1]: Summary of Complications encountered in TURP (total=47) 
The operating time for the series was 48 minutes varying from 29 to $85 \mathrm{~min}$. Mean duration of hospital stay was 3.02 days varying from 48 hours to 7 days. Blood loss was estimated to vary from 0.8 units to 3 units with average of 1.6 units with 3 patients requiring transfusion (6.3\%). The summary of complications encountered is summarized in [Table/Fig-1].

\section{DISCUSSION}

In recent times newer technologies like HoLEP and PVP are replacing TURP as the procedure of choice as treatment of choice for BPH in patients failing medical therapy [8]. However in deprived areas of the world open prostatectomy is still being advocated in view of its safety profile [4]. Development of a urological service with availability of TURP facilities can be achieved with proper training and planning. This requires careful patient selection, expertise accumulation and development of supporting infrastructure $[9,10]$. Studies have shown increasing proportion of patient undergoing TURP in comparison to open prostatectomy [11].

The aim of therapy is to provide effective treatment of bladder outlet obstruction with reduced lifetime risk of adverse consequences. Open prostatectomy is associated with longer hospital stays, more blood transfusion, abdominal wound infections and longer recuperation though slightly lower complication rate overall $[5,10]$. With increasing familiarity with endoscopic procedures and expertise, it is suggested that TURP may easily be used in rural settings as it provides excellent results with moderate initial cost and low recurrent costs $[12,13]$.

Though, some studies show lower cost of PVP over TURP but this is fallacious in our country given the high cost of laser systems and consumables as compared to TURP set up the approximate cost being 4 lakhs with Rs 1000 in consumables in each case [14].

TURP has significant advantages over open prostatectomy having much shorter hospital stay and comparatively lower transfusion rate lower wound dehiscence and 4\% rate of reoperation [15]. The increase in size of prostate is associated with increasing blood loss with an average loss of 1.6 units in this study along with early post op recovery [16]. In a study of complication rates following open prostatectomy Oranusi et al., [17] observed an overall complication rate of $40.1 \%$ with bleeding being the most common- occurring in upto $20.8 \%$ of patients besides wound infections, UTI, clot retention. Late complication rates were $2.8 \%$ with stricture being most common. In this study, 3 patients (6.3\%) of patients required transfusion which is similar to that observed be Bachmann et al., [18]. Al Hasan et al., had a post op transfusion rate of $0.8 \%$ for all patients where as 30\% patients had needed pre operative transfusion. In our study $6.3 \%$ of patients needed transfusion with bleeding seen in $12 \%$ of patients which is quite less as compared to those seen in open surgery [17]. Intra and postoperative blood loss is one of the concerns TURP. Studies have compared blood loss variation with types of anaesthesia or comparison with LASER resection [7]. Shreshta had a blood loss range of $21 \mathrm{ml}$ to $1251 \mathrm{ml}$ in TURP with average loss of $188.5 \mathrm{ml}$ and an operating time range of 10 to 65 min [19]. In an analysis of 536 TURPs, Cumpanas et al., in a 6 year study of residents showed a faster operating time with lower complications later in the study curve which emphasizes proper training [6].

Ceylan et al., had a total complication rate of $34.6 \%$ with $20.3 \%$ early complications comparable to results seen in our study $[4,15]$. With improvement in technology there has been significant reduction in complications associated with TURP with a long term morbidity of less than $1 \%[20,21]$.

Increasing experience with exposure to both open and TURP for larger prostatic size allows a flexible approach for TURP in ever larger size prostate as stated by urosurgeons who regularly operate on larger size prostate. In our study we had an upper limit of 80 grams after which open prostatectomy is preferred [22]. Some workers have found increased size of prostate with greater incidence of LUTS in such patients [23]. In our study $8 \%$ of patients had associated diabetes which is similar to crude prevalence rate of up to $9 \%$ as per $\mathrm{WHO}$ data. In an Iranian study comparing postoperative outcomes of turp on diabetics and non diabetics found no significant differences in prostatic volumes. TURP was found to be safe and beneficial except retreatment rates were slightly higher in diabetics [24]. No such differences were seen in this study.

HoLEP is an attractive alternative to TURP and useful in larger size prostate with less blood loss and early discharge but is prohibitively expensive for our situation in resource poor areas at present [25].

\section{LIMITATION}

One of the limitations of this study is that this is an observational study with limited numbers of patients undergoing TURP, there is lack of good studies determining cost using newer modalities with adequate number of patients in similar conditions. Another short coming is that the follow up duration is short.

\section{CONCLUSION}

The stumbling block in greater availability of TURP in rural areas is lack of resources and the lack of expertise. In our settings instruments are available and all that is required is supporting facility and trained personnel with proper supervision. This is a small observational study with 47 patients undergoing TURP with good outcomes. This is especially true in our situation where recurring costs are less and the initial cost can be amortized over number of cases. In order to determine the cost advantages and safety of TURP or Laser prostatectomy a prospective study with good number of patients is needed. 


\section{REFERENCES}

[1] Jacobsen SJ, Girman CJ, Lieber MM. Natural history of benign prostatic hyperplasia. Urology. 2001;58(6 Suppl 1):5-16; discussion 16. Review. PubMed [citation] PMID: 11750242.

[2] Roehrborn CJ, Marks L, Harkaway R. Enlarged prostate: a landmark national survey of its prevalence and impact on US Men and their partners. Prostate Cancer Prostatic Dis. 2006;9(1):30-34.

[3] Lu-Yao GL, Barry MJ, Chang CH, Wasson JH, Wennberg JE. Transurethral resection of the prostate among medicare beneficiaries in the United States: time trends and outcomes. Prostate patient outcomes research team (PORT). Urology. 1994;44(5):692-98; discussion 698-99. Review. PubMed [citation] PMID: 7526526

[4] Ceylan, K. Open prostatectomy the results of a series of 320 casaes in rural area. Eur J Gen Med. 2006;3(1): 11-15.

[5] Reich O, Gratzke C, Stief CG. Techniques and long-term results of surgical procedures for BPH. Eur Urol. 2006 ;49(6):970-78; discussion 978. Epub 2006 Feb 6. Review. PubMed [citation] PMID: 16481092.

[6] Cumpanas A. Botoca M. Bucuras V. Claici D. Boiborean P. Miclea F. \& Dragan $P$. The learning curve in transurethral resection of prostate (TURP)-The experience of eight young urologists during a six-years period. Timisoara Medical Journal. 2004, 54, 159-63.

[7] Chukwujama N. O. Oguike T. \& Azike J. Transurethral resection of the prostate: a 3 year experience. Nigerian Journal of Surgery. 2011, 17(1), 15-18

[8] Harkaway RC, Issa MM. Medical and minimally invasive therapies for the treatment of benign prostatic hyperplasia. Prostate Cancer Prostatic Dis. 2006;9(3):204-14.

[9] Namdarian B, Willder S, Steele G, Leona R, Grills R. Establishment of a urology service in a developing country: an observational study of outcomes in transurethral prostate resection procedures in Vanuatu. Lancet. 2015 27;385 (Suppl 2):S26. doi: 10.1016/S01406736(15)60821-2. Epub 2015 Apr 26.

[10] Kiptoon DK, Magoha GA, Owillah FA. Early postoperative outcomes of patients undergoing prostatectomy for benign prostatic hyperplasia at Kenyatta National Hospital, Nairobi. East Afr Med J. 2007;84(9 Suppl):S40-44.

[11] Ibrahim AIA, el-Malik E, Ghali AM, Murad N, Saad M. Effect of age, comorbidity and type of surgery on perioperative complications and mortality of prostatectomy. Br J Urol. 1995;76(3):341-45.

[12] Kuntz RM. Current role of lasers in the treatment of benign prostatic hyperplasia (BPH). Eur Urol. 2006;49(6):961-69. Epub 2006 Mar 31. Review. PubMed [citation] PMID: 16632179

[13] Alhasan SU, Aji SA, Mohammed AZ, Malami S. Transurethral resection of the prostate in Northern Nigeria, problems and prospects. BMC Urol. 2008;8:18.
[14] Stovsky MD, Griffiths RI, Duff SB. A clinical outcomes and cost analysis comparing photoselective vaporization of the prostate to alternative minimally invasive therapies and transurethral prostate resection for the treatment of benign prostatic hyperplasia. J Urol. 2006;176(4 Pt 1):1500-06.

[15] Ngugi PM, Saula PW. Open simple prostatectomy and blood transfusion in Nairobi. East Afr Med J. 2007;84(9 Suppl):S12-23.

[16] Gupta S, Gupta A, Saha S, Mahapatra L, Srivastava U. Outcome of surgery for benign prostatic hyperplasia-is it predictable? J Clin Diagn Res. 2013;7(12):2859-62. doi: 10.7860/JCDR/2013/7606.3888. Epub 2013 Nov 18. PubMed [citation] PMID: 24551658, PMCID: PMC3919415.

[17] Oranusi CK, Nwofor A, Oranusi IO. Complication rates of open transvesical prostatectomy according to the Clavien-Dindo classification system. Niger J Clin Pract. 2012;15(1):34-37. doi: 10.4103/1119-3077.94094

[18] Bachmann A, Schürch L, Ruszat R, Wyler SF, Seifert HH, Müller $A$, et al. Photoselective vaporization (PVP) versus transurethral resection of the prostate (TURP): a prospective bi-centre study of perioperative morbidity and early functional outcome. Eur Urol. 2005;48(6):965-71; discussion 972. Epub 2005 Jul 18. PubMed [citation] PMID: 16126327.

[19] Shrestha BM, Prasopshanti K, Matanhelia SS, Peeling WB. Blood loss during and after transurethral resection of prostate: a prospective study. Kathmandu Univ Med J (KUMJ). 2008;6(23):329-34. PMID: 20071814

[20] Rassweiler J, Teber D, Kuntz R, Hofmann R. Complications of transurethral resection of the prostate (TURP)--incidence, management, and prevention. Eur Urol. 2006;50(5):969-79.

[21] Wendt-Nordahl G, Bucher B, Häcker A, Knoll T, Alken P, Michel MS. Improvement in mortality and morbidity in transurethral resection of the prostate over 17 years in a single center. J Endourol. 2007;21(9):1081-87. PubMed [citation] PMID: 17941791.

[22] Persu C, Georgescu D, Arabagiu I, Cauni V, Moldoveanu C, Geavlete P. TURP for BPH. How Large is Too Large? Journal of Medicine and Life. 2010; 3(4): 376-80.

[23] Stamatiou K, Lardas M, Kostakos E, Koutsonasios V, Michail E. The impact of diabetes type 2 in the pathogenesis of benign prostatic hyperplasia: a review. Adv Urol. 2009; 818965:1-3.

[24] Soleimani M, Hoseini SY, Aliasgari M, Dadkhah F, Lashay A, Amini E. Long-term outcome of trans urethral prostatectomy in benign prostatic hyperplasia patients with and without diabetes mellitus. $J$ Pak Med Assoc. 2010;60(2):109-12. PMID: 20209696.

[25] Michalak J, Tzou D, Funk J. HoLEP: the gold standard for the surgical management of BPH in the 21(st) Century. Am J Clin Exp Urol. 2015;3(1):36-42.

\section{AUTHOR(S):}

1. Dr. Amit Kumar

2. Dr. Devendra Kumar Shiwach

\section{PARTICULARS OF CONTRIBUTORS:}

1. Assistant Professor, Department of Surgery, Rama Medical College Hospital and Research Centre, Hapur, India.

2. Assistant Professor, Department of Surgery, Rama Medical College Hospital and Research Centre, Hapur, India.

\section{NAME, ADDRESS, E-MAIL ID OF THE} CORRESPONDING AUTHOR:

Dr Amit Kumar,

105, Staff Quarter, Rama Medcial College, NH 24,

Pilkhuwa, Hapur, Uttar Pradesh-245304, India.

E-mail: dramitkr@hotmail.com

FINANCIAL OR OTHER COMPETING INTERESTS: None. 